\title{
Impressum, Vol. 12, No. 6, 1989
}

\section{Herausgeber}

\section{S. Karger}

Verlag für Medizin und Naturwissenschaften GmbH, Postfach 1724, D-8034 Germering

Presserechtlich verantwortlich: Walter Kunz, Gesellschafter

Wissenschaftlicher Beirat

H.W. Bauer, Berlin; W. Bossnev, Sofia/Bulgarie $\pi$; H. Denck, Wien; V. Diehl, Köln; P. Drings, Heidelberg; E. Dühmke, Göttio-gen; S. Eckhardt, Budapest; H. Ehrhart, München; H.H. Fiebig, Freiburg; W.M. Gallmeier, Nürnberg; E.H. Graul, Marburg/ Lahn; R. Hartenstein, München; H. Heimpel, Ulm; K.P. Hellrie-gel, Berlin; Ch. Herfarth, Heidelberg; H.W. von Heyden, Ein-beck; D. Hoelzer, Frankfurt/M.; J.H. Holzner, Wien; R. Hünig, Basel; W. Hunstein, Heidelberg; H.J. Illiger, Oldenburg; N. Jaeger, Bonn; W.F. Jungi, St. Gallen; U.R. Kleeberg, Hamburg; H.O. Klein, Köln; B. Kornhuber, Frankfurt/M.; H. Löffler, Kiel; U. Mohr, Hannover; K. Munk, Heidelberg; G.A. Nagel, Göttin-gen; J.P. Obrecht, Basel; A. Pfleiderer, Freiburg; K. Possinger, München; W. Queißer, Mannheim; H. Riehm, Hannover; J. Roth, Basel; E. Scherer, Essen; H.-J. Schmoll, Hannover; M. Schroder, Kassel; S. Seeber, Leverkusen; A. Stacher, Wien; V. Sturm, Köln; St. Tanneberger, Berlin/DDR; W. Vahlensieck, Bonn; H.D. Waller, Tubingen; M.

Wannenmacher, Heidelberg; W. Wilmanns, München; K. Wilms, Würzburg; K. zum Wịnkel, Heidelberg; H. Wrba, Wien.

Schriftleitung: S. Eckhardt, Budapest J.H. Holzner, Wien W. Queißer, Mannheim Die Zeitschrift erscheint zweimonatlich; pro Jahr erscheint 1 Band zu je 6 Heften. Bezugspreis für Jahrgang 12, 1989, DM 148,-/öS 1036,-/SFr 116,-. 1 Einzelheft kostet DM 28,/öS 196,-/SFr 22,-, einschließlich MwSt., zuzüglich Postgebühren.

Der Abonnementpreis ist im voraus zahlbar. Das Abonnement der Zeitschrift läuft weiter, wenn es nicht spätestens 4 Wochen vor Abschluß eines Bandes abbestellt wird.

Abonnementbestellungen können bei jeder Buchhandlung oder direkt beim Verlag aufgegeben werden:

Bundesrepubiik DeutschiandlÖsterreich: S. Karger GmbH, Postfach 1724, D-8034

Germering/München. Tel.: (089) 843035, Telex: 524865 D, Telefax: 8418083, Postgirokonto:

München 40080-807

Schweiz: S. Karger AG, Allschwilerstr. 10, Postfach, CH-4009 Basel, Tel.: (061) 390880, Telex $62652 \mathrm{CH}$, Telefax (061) 385383

Anzeigen

S. Karger Verlag für Medizin und Naturwissenschaften GmbH, Postfach 1724, D-8034 Germering, Telefon (089) 843035. Gültig ist die Preisliste Nr. 5 vom 1.10.1986.

Für den Inhalt außerhalb des redaktionellen Teiles (insbesondere Anzeigen, Industrieinformationen, Pressezitate und Kongreß-informationen) übernehmen Schriftleitung, Beirat und Verlag keine Gewähr.

Eine Markenbezeichnung kann warenzeichenrechtlich geschützt seín, auch wenn bei ihrer Verwendung in dieser Zeitschrift das Zeichen ${ }^{\circledR}$ oder ein anderer Hinweis auf etwa bestehende 
Schutz-rechte fehlen sollte. Für Satzfehler, insbesondere bei Dosierungs-angaben, wird keine Gewähr übernommen.

Die Zeitschrift sowie alle in ihr enthaltenen einzelnen Beiträge und Abbildungen sind urheberrechtlich geschützt. Jede Verwer-tung, die nicht ausdrücklich vom Urheberrechtsgesetz zugelassen ist, bedarf der vorherigen Zustimmung des Verlags. Das gilt insbesondere für Vervielfältigungen, Bearbeitungen, Übersetzun-gen, Mikroverfilmungen und die Einspeicherung und Verarbei-tung in elektronischen Systemen. Fotokopien dürfen nur für den persönlichen Gebrauch als Einzelkopien hergestellt werden. Jede im Bereich eines gewerblichen Unternehmens zulässig hergestellte oder benutzte Kopie dient gewerblichen Zwecken gem. § 54(2) UrhG und verpflichtet zur Gebührenzahlung an die Verwertungs-gesellschaft WORT, Abt. VG Wissenschaft, Goethestraße 49, D-8000 München 2.

(C) Copyright 1989 by S. Karger Verlag für Medizin und Naturwissenschaften GmbH, Postfach 1724, D-8034 Germering

Satz und Druck: Walter Biering GmbH, Grafischer Betrieb, Freisinger Landstr. 21, D-8000

München 45

Offizielles Organ

der Deutschen Gesellschaft für Hämatologie und Onkologie,

der Österreichischen Gesellschaft fur Hämatologie und Onkologie, der Österreichischen Krebsgesellschaft-Krebsliga 